\title{
Late pulmonary metastases of renal cell carcinoma immediately after post-transplantation immunosuppressive treatment: a case report
}

\author{
Jose Manuel Cozar1 ${ }^{1}$ Natalia Aptsiauri², Miguel Tallada1 ${ }^{1}$, Federico Garrido ${ }^{2}$ \\ and Francisco Ruiz-Cabello*2
}

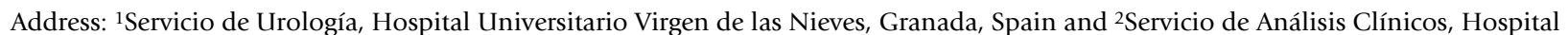
Universitario Virgen de las Nieves, Granada, Spain

Email: Jose Manuel Cozar - cozarjm@supercable.es; Natalia Aptsiauri - naptsiauri@hotmail.com;

Miguel Tallada - miguel.tallada.sspa@juntadeandalucia.es; Federico Garrido - federico.garrido.sspa@juntadeandalucia.es; Francisco RuizCabello* - fruizc@ugr.es

* Corresponding author
\end{abstract}

Journal of Medical Case Reports 2008, 2:1II doi:I0.1 186/1752-1947-2-1II

This article is available from: http://www.jmedicalcasereports.com/content/2/I/III

(c) 2008 Cozar et al; licensee BioMed Central Ltd.

This is an Open Access article distributed under the terms of the Creative Commons Attribution License (http://creativecommons.org/licenses/by/2.0), which permits unrestricted use, distribution, and reproduction in any medium, provided the original work is properly cited.

\begin{abstract}
Introduction: We report a case of pulmonary metastatic recurrence of renal adenocarcinoma soon after radical nephrectomy that was followed by renal transplant and immunosuppressive medication. Increased risk of metastatic recurrence of renal cell carcinoma should be considered in the immediate post-transplant period when immunosuppressive medication is administered, even if nephrectomy had been performed many years earlier.

Case presentation: In 1986 the patient demonstrated renal insufficiency secondary to mesangial glomerulonephritis. In 1992 he underwent left side radical nephrectomy with histopathological diagnosis of clear cell adenocarcinoma. Mesangial glomerulonephritis in the remaining right kidney progressed to end-stage renal failure. In October 2000 he received a kidney transplant from a cadaver and commenced immunosuppressive medication. Two months later, several nodules were found in his lungs, which were identified as metastases from the primary renal tumor that had been removed with the diseased kidney 8 years earlier.
\end{abstract}

Conclusion: Recurrence of renal cell carcinoma metastases points to tumor dormancy and reflects a misbalance between effective tumor immune surveillance and immune escape. This case demonstrates that a state of tumor dormancy can be interrupted soon after administration of immunosuppressant medication.

\section{Introduction}

Renal cell carcinoma (RCC) is the most common renal malignancy [1]. Late recurrence of metastatic renal carcinoma has previously been described [2-5]. The greatest risk of recurrence for RCC occurs within the first 5 years after nephrectomy [6]. Although, recurrences have been reported as late as 30 years following nephrectomy, rates of $43 \%$ in the first year, $70 \%$ within the second year, $80 \%$ within 3 years, and $93 \%$ within 5 years have been reported $[7,8]$. After nephrectomy, the incidence of RCC recurrence has been reported to be $7 \%$ with a median time of 38 months for T1 tumors, $26 \%$ with a median time of 32 
months for $\mathrm{T} 2$ disease, and $39 \%$ with a median time to recurrence of 17 months for T3 tumors [9]. RCC has been shown to metastasize to almost all soft tissues in the body, but most commonly to the lung, followed by bone, liver, brain, and local recurrence [10]. RCC metastases occur frequently in the lung, affecting $3 \%$ to $16 \%$ of patients after nephrectomy $[8,9,11]$.

It is well known that patients who have undergone solid organ transplantation and are taking immune suppressing drugs to prevent organ rejection are at a higher risk of getting cancer [12]. The most common malignancies are lymphoproliferative disorders (early after transplantation) and skin carcinomas (later after transplantation). In kidney transplant recipients, renal cell carcinoma (RCC) may occur either in the native kidney or, less frequently, in the grafted kidney $[13,14]$. High risk of metastatic recurrence in immunosupressed patients is often associated with interruption of tumor dormancy and proliferation of residual tumor cells that had survived the anti-tumor immune reactivity because of low immunogenicity $[15,16]$. Cancer patients with tumor dormancy can have an apparent balance between tumor cell replication and cell death, reflecting a balance between effective immune surveillance and immune escape [17].

Here we report a case of late and aggressive pulmonary metastatic progression of renal cancer in an immunosupressed patient soon after renal transplantation and many years after the initial removal of a malignant kidney. We believe that immunosuppressive medication provoked rapid metastatic recurrence in this patient.

\section{Case presentation}

A 43-year-old male patient with a previous history of arterial hypertension and cholecystectomy for gallstone disease, presented in our clinic in 1986 with renal insufficiency secondary to mesangial glomerulonephritis and without any evidence of a renal mass as analyzed by sonography. In 1992, a renal mass on the left side, compatible with renal adenocarcinoma, was detected during a surveillance annual abdominal sonography and was later confirmed by CT scan. The diameter of the lesion was $5 \times$ $5 \mathrm{~cm}$. The same year, the patient underwent left side radical nephrectomy with histopathological diagnosis of clear cell adenocarcinoma pT2pNOMO (primary tumor localized in the kidney parenchyma without metastases in the regional lymph nodes and without distant metastases according to "tumour-node-metastasis" (TNM) classification. Mesangial glomerulonephritis in the remaining right kidney progressed to end-stage renal failure. In 2000, the patient had peritoneal dialysis and, because thoracoabdominal CT examination revealed no signs of local or distant renal tumor recurrence, the patient was recommended for renal transplantation.
In October 2000, he received a renal transplant from cadaver and started immunosuppressive medication. The regimen included: Prednisolone, Tacrolimus (calcineurin inhibitor) and Mycophenolate. The immunosupression was not augmented since there were no signs of rejection.

In December of the same year, the patient presented with spontaneous pneumothorax on the left side and underwent pleural punction and aspiration. CT scan showed disseminated pulmonary nodules (Figure 1) with mediastinal adenopathy. Abdominal CT scan showed a functional transplanted right kidney without malignant lesions. There were no signs of tumor recurrence in the kidneys. Bone scintigraphy was negative for metastases. Histological analysis of biopsies of pleural parietal and pulmonary nodules from the left lung identified them as metastases from clear cell renal carcinoma. DNA microsatellite analyses using AmpFISTR Profiler Plus PCR Amplification Kit (PE Applied Biosystems, Madrid, Spain) (Figure 2) demonstrated that the metastatic lesions did not originate from the donor kidney but from the the primary renal tumor removed with the diseased kidney 8 years earlier. Importantly, these metastatic nodules appeared two months after initiation of immunosuppressive treatment. It was decided to remove the transplant and stop the immunosuppressive medication. The patient was commenced on hemodialysis. In February 2001, immunotherapy with IL-2 and IFN-alpha was initiated, which was well tolerated by the patient. In August 2001, chest CT demonstrated enlargement and progression of the pulmonary metastases. The patient presented with asthenia, anorexia, anemia and bone pain, and he was referred to the Pain Care Unit. In October 2001, one year after commencement of immunosuppressive medication, the patient died.

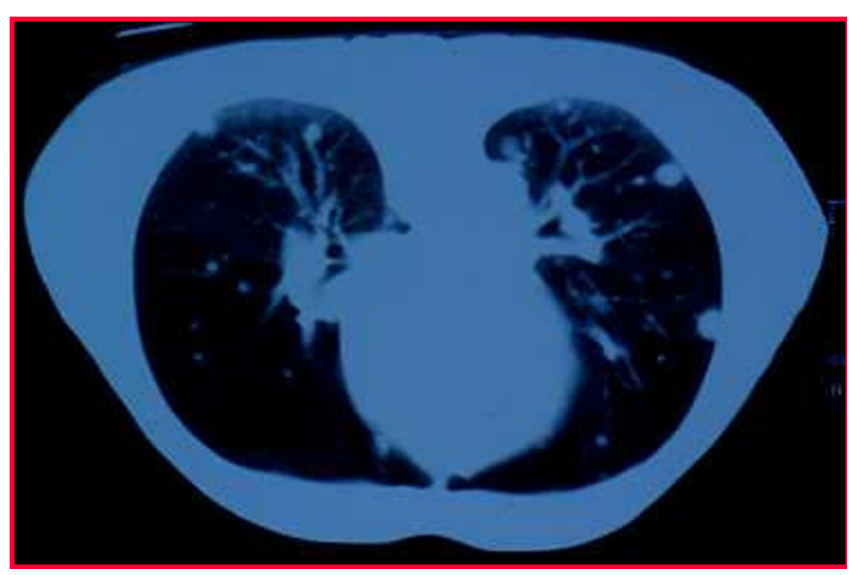

Figure I

CT scan demonstrating pulmonary nodules. 


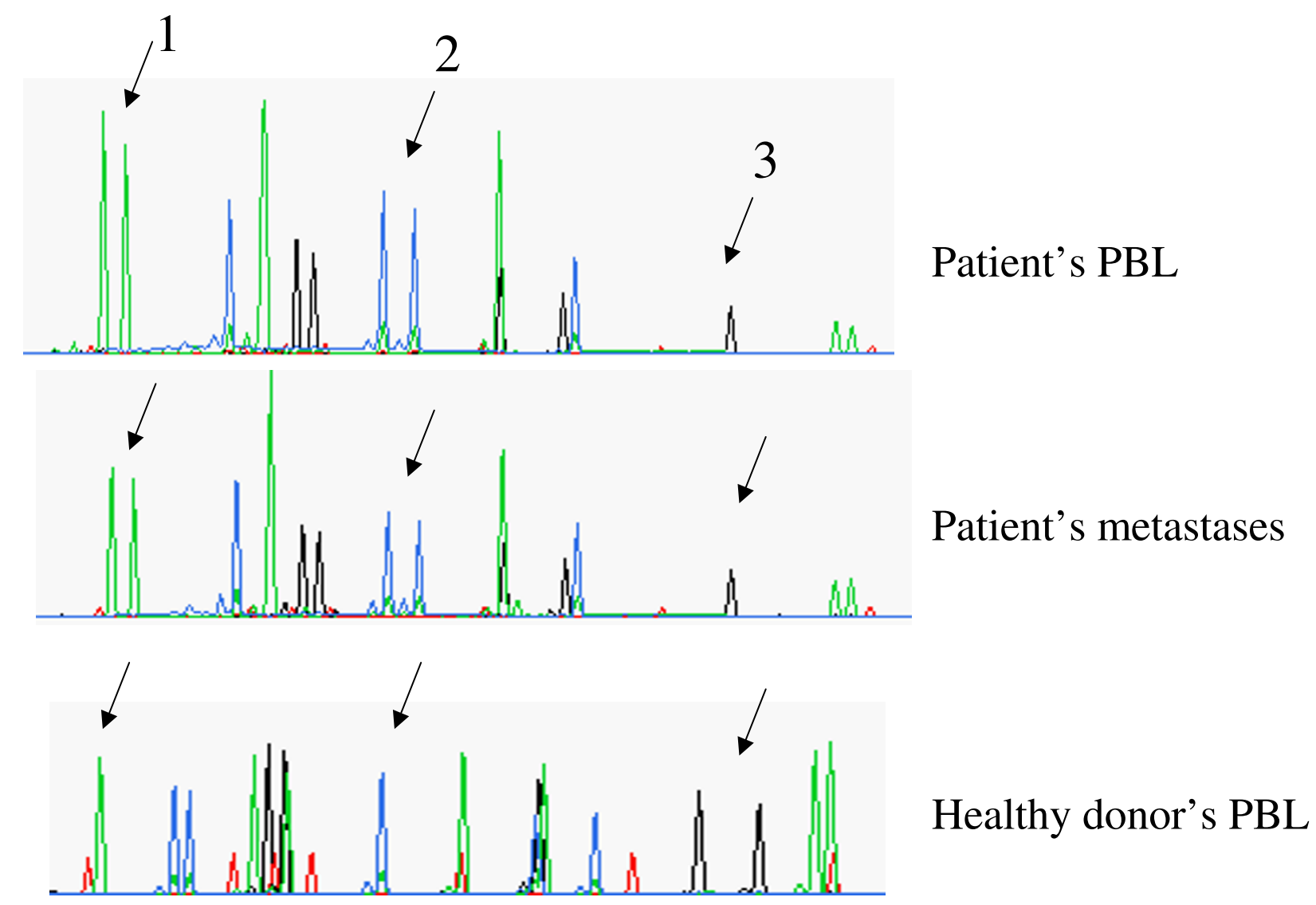

Figure 2

Microsatellite analysis showing similar profile between metastases and peripheral blood lymphocytes (PBL)s of the patient. This assay is commonly used for linkage mapping studies, association studies, and identification of organisms. It has been reported to be useful for assessment of chimerism in graft-versus-host disease, for identification of the site of origin of unknown primary tumor, and for determination of donor-recipient origin in posttransplant lymphoproliferative disorders. Microsatellites are short runs of tandemly repeated DNA that represent a primary source of human genetic diversity. The variations in these repeats are used for genetic identification purposes. It is based on PCR amplification of various microsatellite loci (or markers) using fluorescently labeled forward and unlabeled reverse primers. The PCR amplicons are separated by size and the labeled products are identified using fluorescence detectors. In this case the DNA was extracted from pulmonary metastases, patients PBLs, and from healthy donor PBLs. Arrows indicate differences in the microsatellite markers used: I Amelogenin locus in $X / Y$ chromosomes (patient and metastases have $X Y$ profile (male), donor has $X X$ profile (female)); 2 locus vWA in chromosome 12p (heterozygous in patient's PBLs and metastases, homozygous in donor PBLs); 3 - D7S820 marker in chromosome 7q (homozygous in patient's BPLs and metastases, heterozygous in donor PBLs).

\section{Discussion}

It is well documented that metastatic recurrence is a frequent cause of cancer development even many years after removal of primary tumor [6]. It is also well known that immunosuppressive therapy in post-transplantation patients frequently induces various de novo cancers [12]. We believe that in our case tumor dormancy of residual malignant cells that lasted for 8 years, had been interrupted after the changes in the patient's immune status immediately following kidney transplantation and immunosuppressive regime. Persistence of circulating tumor cells may represent residual disease and is known to be associated with a higher risk of recurrence; however, the status of tumors during the period of dormancy is poorly understood. Various factors have been identified as possible contributors to tumor dormancy and subsequent recurrence, including tumor angiogenesis, cell proliferation and cell cycle arrest, cancer cell interactions with the microenvironment, and changes in immune status [18]. Various published results have described that oncogene inactivation can induce tumor regression and that oncogene reactivation leads to rapid tumor formation. There 
are reports demonstrating that at least in some cases tumor dormancy can be interrupted by a transient change in the microenvironment due to local inflammation. Animal studies also indicate the importance of T-cell immunity in the induction and maintenance of tumor dormancy. Dormant micrometastases may be triggered to expand when host or cancer cell factors change to promote progressive metastatic growth. In our case the immunosupression was a probable trigger of such expansion. Tumor dormancy represents an existence of an apparent balance between tumor cell elimination and proliferation, or between effective immune surveillance and immune escape. According to the theory of immunosurveillance, originally proposed by Burnet and Thomas in 1957, the immune system protects the host against tumor development by recognizing and eliminating transformed cells, therefore, the dysfunction of the immune system leads to increased risk of cancer incidence. Published data obtained from more recent mouse models and from human clinical trials supports this theory and suggests the existence of a more complex picture of immunosurveillance, which includes an active role of the immune system also in facilitating immunoselection of malignant cells and the emergence of tumor escape variants with low immunogenicity. New data indicate that the immune system can facilitate tumor progression, at least in part, by sculpturing the immunogenic phenotypes of tumors as they develop [19]. It has been confirmed in animal studies that tumors developing in immunodeficient mouse strains tend to be more immunogenic, while tumor cells arising in the presence of a fully functional immune system are less immunogenic. Thus, in the case of a functional immune system highly immunogenic tumor cells that are recognized by the immune system are eliminated while tumor variants that have better survival features, such as low immunogenicity, are selected. This selective pressure leads to the expansion of a new population of cells with multiple defects capable of evading immune response. These residual tumor cells may be circulating in patients in long remissions and they may represent a different stage of tumor control mechanisms, called an immunological equilibrium. Some of the immune escape mechanisms, notably downregulation of MHC class I molecules that are necessary for antigen presentation of tumor specific peptides to cytotoxic T-lymphocytes, are most pronounced in metastatic lesions, as it has been demonstrated in RCC [20]. This suggests that the selection pressure is strong in the metastatic stage of cancer development. Thus, the immune system might play a dual role: protecting the host by eliminating strong variants of tumor cells and promoting tumor development by selection of immunologically weak tumor variants that give rise to a new metastatic progression. Therefore, the immune system can maintain a subclinical tumor in an equilibrium state. We propose that a stage of immunolog- ical equilibrium between tumor growth and elimination had been reached in our patient after the excision of the malignant kidney. After transplantation, the administration of immunosuppressants changed the immunological equilibrium and probably triggered the pulmonary metastatic malignant growth of dormant tumor cells from the primary renal carcinoma. This supports the importance of immune surveillance as part of tumor-host interaction during cancer progression and the key role of tumor escape in immunosupressed individuals.

\section{Conclusion}

In conclusion, this case demonstrates that dormant metastases can develop in immunocompromised cancer patients soon after administration of immunosuppressive medication even after a long cancer-free and metastasisfree period following removal of the primary tumor.

\section{Competing interests}

The authors declare that they have no competing interests.

\section{Authors' contributions}

JMC and MT are urologists who treated the patient for many years. NA, FG and FRC are immunologists who performed microsatellite analysis, analyzed the data and drafted the manuscript. All authors read and approved the final manuscript.

\section{Consent}

Written informed patient consent was obtained for publication of this case report and accompanying images. A copy of the written consent is available for review by the Editor-in Chief of this journal.

\section{Acknowledgements}

This work was partially supported by the Fondo de Investigaciones Sanitarias (PI 02/0175), the plan Andaluz de Investigacion, and the Instituto de Salud Carlos III-Red de centros de Cancer, Spain.

\section{References}

I. Curti BD: Renal cell carcinoma. JAMA 2004, 292:97-I00.

2. Featherstone JM, Bass P, Cumming J, Smart C): Solitary, late metastatic recurrence of renal cell carcinoma: two extraordinary cases. Int J Urol 2006, I 3(I 2): I 525-I527.

3. Uemura T, Kurita A, Nishimura R, Ishizaki M, Takashima S: Solitary pancreatic metastasis from renal cell carcinoma concomitant with early gastric cancer 17 years after nephrectomy: report of a case. Surg Today 2003, 33(5):395-398.

4. Moudouni SM, Tligui M, Doublet JD, Haab F, Gattegno B, Thibault P: Late metastasis of renal cell carcinoma to the submaxillary gland 10 years after radical nephrectomy. Int J Urol 2006, I3(4):431-2.

5. Shiono S, Yoshida J, Nishimura M, Nitadori J, Ishii G, Nishiwaki Y, Nagai K: Late pulmonary metastasis of renal cell carcinoma resected 25 years after nephrectomy. Jpn J Clin Oncol 2004, 34(I):46-49.

6. Chin Al, Lam JS, Figlin RA, Belldegru AS: Surveillance Strategies for Renal Cell Carcinoma Patients Following Nephrectomy. Rev Urol 2006, 8(I): I-7.

7. McNichols DW, Segura JW, DeWeerd JH: Renal cell carcinoma: long-term survival and late recurrence. J Urol 1981, I 26:17-23. 
8. Ljungberg B, Alamdari FI, Rasmuson T, Roos G: Follow-up guidelines for nonmetastatic renal cell carcinoma based on the occurrence of metastases after radical nephrectomy. BJU Int 1999, 84:405-4I].

9. Levy DA, Slaton JW, Swanson DA, Dinney CP: Stage specific guidelines for surveillance after radical nephrectomy for local renal cell carcinoma. J Urol I998, 159: I |63-I I67.

10. Lam JS, Leppert JT, Figlin RA, Belldegrun AS: Surveillance following radical or partial nephrectomy for renal cell carcinoma. Curr Urol Rep 2005, 6:7-18.

11. Stephenson AJ, Chetner MP, Rourke K, Gleave ME, Signaevsky M, Palmer B, Kuan J, Brock GB, Tanguay S: Guidelines for the surveillance of localized renal cell carcinoma based on the patterns of relapse after nephrectomy. J Urol 2004, I72:58-62.

12. Penn I: Cancer in renal transplant recipients. Adv Ren Replace Ther 2000, 7(2): 147-156.

13. Barama A, St-Louis G, Nicolet V, Hadjeres R, Daloze P: Renal cell carcinoma in kidney allografts; a case of series from a single center. Am J Transplant 2005, 5(I 2):3015-30 I8.

14. Neuzillet WJ, Lay F, Luccioni A, Daniel L, Berland Y, Coulange C, Lechevallier $\mathrm{E}$ : De novo renal cell carcinoma of native kidney in renal transplant recipients. Cancer 2005, 103(2):25I-257.

15. Uhr JW, Scheuermann RH, Street NE, Vitetta ES: Cancer dormancy: opportunities for new therapeutic approaches. Nat Med 1997, 3(5):505-509.

16. Michelson S, Leith JT: Dormancy, regression, and recurrence: towards a unifying theory of tumor growth control. J Theor Biol 1994, 169(4):327-338.

17. Bui JD, Schreiber RD: Cancer immunosurveillance, immunoediting and inflammation: independent or interdependent processes? Curr Opin Immunol 2007, I 9(2):203-208.

18. Aguirre-Ghiso JA: Models, mechanisms and clinical evidence for cancer dormancy. Nat Rev Cancer 2007, 7(I I):834-846.

19. Khong HT, Restifo NP: Natural selection of tumor variants in the generation of "tumor escape "phenotypes. Nat Immunol 2002, 3(II):999-1005.

20. Aptsiauri N, Cabrera T, Garcia-Lora A, Lopez-Nevot MA, RuizCabello F, Garrido F: MHC class I antigens and immune surveillance in transformed cells. International Review of Cytology 2007, 256: 139-189.

Publish with Bio Med Central and every scientist can read your work free of charge

"BioMed Central will be the most significant development for disseminating the results of biomedical research in our lifetime. "

Sir Paul Nurse, Cancer Research UK

Your research papers will be:

- available free of charge to the entire biomedical community

- peer reviewed and published immediately upon acceptance

- cited in PubMed and archived on PubMed Central

- yours - you keep the copyright
BioMedcentral 